\title{
LA MANUMISIÓN DE UN MUSULMÁN: UN DOCUMENTO DOBLE DE VALENCIA EN EL 1300
}

Por

ROBERT 1. BURNS, S.J.

Deben haber habido más de unos cuantos esclavos liberados por sus dueños en el reino de Valencia del siglo XIII. Los Furs del reino les proporcionaban como categoría en los derechos de aduana - «un sarraceno liberado (alforra) que deje el reino: II besants." Esta lista distinguía (y tasaba de manera diferente) al musulmás "liberado" del "rescatado", y del musulmán libre ordinario «que viaje por tierra o por mar» como mudéjar o como visitante extranjero. El término latino allforra, del árabe al-hurr, era técnicamente diferente de $\mathrm{li}$ ber: "liberado" en lugar de "libre". Valencia tenía una alta población de hombres libres mudéjares, pero su cruzada y las revueltas habian asimismo acumulado un gran número de esclavos. El cronista Ramón Muntaner anota que Jaime el Conquistador dió dos mil esclavos musulmanes como regalo al Papa, cardenales, el rey de Francia, y al emperador del Sacro Imperio Romano, "y a condes y barones amigos suyos". En una fecha tan tardía como 1287 existía una gran esclavización de musulmanes de la conquista de la cerna isla de Menorca, y los conflictos en la frontera granadina traerían muchos más.

La documentación referente a la generación de la cruzada es tan escasa sobre el tema de los musulmanes liberados como rica sobre los esclavos y libres. El raro documento que aquí se adjunta es, por tanto, valioso en extremo por sí mismo y como un ejemplar representativo de una clase de cartas privadas durante largo tiempo desaparecidas. Joan de Monso, "notario público de Valencia", to redactó en la ciudad de Valencia el 14 de marzo de 1299; dado que los Furs impusieron el calendario de la Encarnación (estilo florentino), tal año en el sistema actual sería el de 1300. La carta se divide en dos documentos: la manumisión bajo condiciones, y la aceptación por parte del esclavo. 
Se ven en el texto dos peculiaridades. La primera de ellas, que el esclavo era ya un converso; y en segundo lugar, que la condición era de tres años de servicio voluntario como hombre libre.

Si se agrupan, estas circunstancias sugieren que los señores del caso eran reticentes a seguir teniendo un cristiano bautizado como esclavo suyo, aunque tal servidumbre era legal, y de todas formas deseaban recobrar algo de su inversión en el esclavo. La piedad y la economía convergen en un término medio. Valencia había visto un modesto aunque considerable número de conversiones a la religión colonizadora hasta ese momento. Mientras un alto porcentaje de ellas puede ser debido al esperado proceso de culturización colonial, el oportunismo puede haber constituido un motivo más común en el caso de los esclavos. En fecha tan temprana como el año 1246, el año después de la finalización de la cruzada valenciana, los prelados de la Corona de Aragón, en concilio en Tarragona, emitieron un dictamen destinado a desalenta y probar las conversiones de esclavos musulmanes, con el fin de disminuir las falsas conversaciones.

Los propietarios era Bernat Planell "ciudadano y cambista de Valencia", y su esposa, Guillemona, representándose tanto en unión como indivíduos, cada uno de ellos con entera responsabilidad (in solidum). Puesto que hacía algunos años que la profesión de cambista había asumido las funciones de depósito bancario, Bernat debió ser una persona acaudalada de cierta consecuencia. La participación equitativa de su esposa en cada momento de la negociación, aunque característica de otras transacciones de propiedad donde ambos cónyuges disponian de un título en común, es digna de mención. El nombre de la esclava al ser bautizada era Francesca.

El contexto genera! indica que había sido musulmana; un esclavo cristiano no hubiera tenido una baptizate, mientras que un esclavo judío habría sido una rareza, la poderosa comunidad judía valenciana no lo hubiera dejado en esa condición por mucho tiempo. De cualquier modo, no parece que haya existido esclavos no musulmanes en Valencia en este siglo. Que Francesca había sido musulmana se deja explícito, sin embargo, en la disposición de la carta referente a la libertad de emigrar a la «tierra de sarracenos». Tras su conversión, por supuesto, ella era "musulmana" tan sólo desde un punto de vista étnico: al ser teóricamente absorbido en el seno de la comunidad cristiana, un converso seguía distinguiéndose de otros cristianos por sus modelos de conducta, y era por ello discriminados por éstos. Dos franceses, cuyos dueños eran el marido y la mujer en común ("nuestra esclava bautizada»), estaba en persona upresente y recibiendo" la emancipación. Por supuesto, los Furs requerían la presencia de todos los principales antes de que el notario fechara la carta.

Bernat y Guillemona dejaron a Francesca «Libn, quita, y puesta en libertad" (Viber, quitia, alforra), unos adjetivos que más adelante en el documento se convertirán en nombres abstractos (absolutio, remissio, alforria) y se reforzarán con una frase descriotiva relativa a la independencia judicial (sui juris). 
Esto la libraba de toda "cautividad" (siendo éste el origen jurídico de la condición de esclavo) y "servilismo", o estado de servidumbre. No se aplicaba tan sólo en la persona de Francesca, sino también a sus posesiones, muebles o no. En persona y propiedad Francesca era libre, para siempre, de «ir, permanecer y volver", en cualquier profesión o condición (professio) "tanto a tierra de cristianos como de sarracenos". Este permiso permanente para viajar o trasladarse a tierras islámicas sugiere que las autoridades consideraban que Francesca era una conversa convencida, siendo improbable que volviera al Islam. No retuvieron nada suyo sus dueños, y prometieron no demandarla (convenire) ni a ella ni a su propiedad, ante los tribunales o fuera de ellos, sino más bien guardar «silencio sempiterno» respecto a ella.

Habiendo otorgado esta libertad incondicional, Bernat y Guillemona dispusieron, sin embargo, una condición, «que estás obligada a servirnos (servire) durante tres años sucesivos, contados desde este día en adelanten. La palabra "nos" fue insertada después sobre la línea, como una aclaración, certificándola el notario más abajo como una inserción válida. Durante este trienio de servicio libre, Bernat y Guillemona se comprometieron a proveer a Francesca con «comida y bebida, ropa y calzado (calceaticum), en salud como en enfermedad"; las frases nos recuerdan la provisión "victum et vestitum» de los "corodies» monásticos, una taquigrafía jurídica referida al cuidado físico completo. Seguidamente habla Francesca, dirigiéndose a sus dos «señores" (domini) , y aceptando la triple forma de manumisión que se ha expresado. Asímismo, "promete y se compromete en buena fe a observar firme y completamente todo lo dicho previamenten, dejando en garantía todas sus presentes y futuras posesiones. Los tres principales estamparon seguidamente su signa - Bernat, después Guillemona, y después Francesca. Los testigos "Convocados e invitados» eran el sacerdote Guillem de Puiggenestós y Jordà Peric(h). El signum notarial pertenecia a Joan de Monsó de Valencia.

La particularidad del servicio libre no era una condición jurídica, aunque se parece al servitutem servire o al liber homo bona fide serviens del Derecho Romano, donde una persona libre servía como esclavo debido a alguna confusión. No puede identificarse claramente a ninguno de los principales que aquí aparecen, aunque dos o tres hombres llamados Bernat Planell se leen en documentos reales de la década de 1270 y de la de 1280 recibiendo molinos en sátiva, comprando el pueblo de Benimaclet, y dándoseles licencia para exportar mercancía. Joan de Monsó puede conectarse con su homónimo castellano de Penacadell en la década de 1270, o al Arnau de Monsó que sirvió al rey Jaime el Conquistador como administrador de la Valencia al sur del Júcar. Pero Bernat, Guillemona, y Francesca parecen haber sido valencianos ordinarios, perteneciendo su familia a la má mitjana o clase media alta. Su carta ha sobrevivido tan sólo porque entró en los archivos del convento de monjas franciscanas de la Puritat, entre los documentos de propiedades y dones que alli se acumulaban. Es posible que una parte del servicio libre de Francesca fuera legado o transferido de cualquier otra forma al convento; es posible incluso que la misma Francesca entrase a formar parte de él. Cualesquiera que sean las circunstancias por las que la carta ha sobrevivido. se 
trata de un precioso ejemplar de un género o clase de documento que desde aquella lejana generación se nos ha perdido ahora en su mayor parte.

(Traducido por Ovidio Carbonell).

Archivo Histórico Nacional.

Clero: Valencia, Franciscanas: carpeta 3281 , doc. 9.

Valencia 14 march (1299) 1300.

Sit omnibus notum [quod] nos, Bernardus Planelli civis et campsor Valencie et uxor eius Guillamona, ambo insimul et uterque nostrum in solidum. bonis animis nostris et spontaneis voluntatibus et a toto iure nostro, certificati penitus et instructi, cum testimonio huius publici instrumenti suo robore valituri, absolvimus et difinimus et omnino nunc et imperpetuum liberam, quitiam, et alforram facimus te Francischam babtizatam, captivam nostram presentem et recipientem, ab omni captivitate et servitute nostra et nostrorum.

Ita quod, ex nunc sicut ex tunc et ex tunc sicut ex nunc, possis ire, stare, et redire, in quacumque professione steteris, tam ad terram Christianorum quam Sarracenorum, tanquam personam liberam, quitiam, et alforram et sui iuris, nulla in te sive super te aut in bonis tuis facta retencione sive iuris proprietate aliqua racione.

Promittentes igitur, bona fide et stipulacione sollempni, quod nunquam te vel bona tua conveniemus seu conveniri faciemus aut valeamus, in curia vel extra curiam aut in iudicio vel extra iudicium, alicubi ullo modo; immo cum omnibus bonis tuis mobilibus et immobilibus, ubique habitis et habendis, sis ab omni captivitate et servitute nostra et nostrorum libera perpetuo et immunis ac penitus et imperpetuum absoluta; facientes inde tibi et tuis finem et pactum tam reale quam personale de perpetuo aliquid non petendo sive de non agendo in iure vel extra iurs [ = ius]; seu eciam ubique inponentes inde nobis et nostris super predictis omnibus et singulis silencium sempiternum, sicut melius, plenius, sanius, ac utilius potest dici, scribi, et intelligi ad commodum et salvamentum tui et tuorum perpetuo.

Tamen retinemus et excipimus a presenti absolucione, remissione, et alforria, quod tu tenearis nobis $/^{3}$ servire per tres annos continue, computandos ab hac die in antea; et nos per totum tempus predictum provideamus te in cibo et patu, vestitu, et calciatu, tam in egritudine quam sanitate ut consimilis cui interest ad hoc.

Ego dicta Francischa recipio a vobis dictis Bernardo Planelli et Guillamona dominis meis dictam absolucionem, remissionem et alforriam in forma et condicionibus supradictis; promittens et bona fide conveniens predicta omnia: et singula a me attendenda et complenda sic vobis et vestris attendere firmi- 
ter et complete, prout superius sunt expressa sine contradictu aliquo in bona pace; obligando scienter ad hoc vobis et vestris omnia bona mea mobilia et inmobilia ubique habita et habenda.

Quod est actum Valencie, pridie idus Marcii, in anno domini MCCXC nono.

Sig + num Bernardi Planelli, sig + num Guillamone uxoris eius, sig + num Francische, predictorum qui hec concedimus et firmamus.

Testes fuerunt huic instrumento, vocati et rogati: Guillelmus de Podio Genestos presbiter, et lordanus Peric.

Sig + num lohannis de Montessono, notarii publici Valencie, qui hoc scribi fecit et cum supraposito in $X^{a}$ linea, ubi dicitur nobis, clausit.

(1) Fori antiqui Valentiae, ed. Manuel Dualde Serrano (Vatencia: 1967), rub. CXUIV, nos. 4 y 15. Muntaner, Crónica, cap. 13, en Les quatre grans cròniques, ed. Ferran Soldevila (Barcelona: 1983). Sobre la esclavitud en Valencia en esta época véase mi Islam Under the Crusaders: Colonial Survival in the ThirteenthCentury Kingdom of Valencia (Princenton University: 1973), cap. 5, parte 4. a asi como los trabajos de Charles Verlinden, S.D. Goitein, y otros que allí se citan. Véase además Johannes Vincke, "Königtum und Sklaverei im aragonischen Staatenbund während des 14. Jahrhunderts", Gesammelte Aufsätze zur Ku/turgeschichte Spaniens, XXV (1970), 1-112; su apéndice documental nos ofrece una manumisión de catorce musulmanes leridanos por Jaime l en Septiembre de 1257, para ensanchar la aljama de Huesca, y otra por Alfonso lV de dos musulmanes en agosto de 1329 (nos 1 y 21 ). Más recientemente, véase M.T. Ferrer i Mallol, Els sarrains de la corona catalano aragonesa en ef segle XIV (Barcelona: 1987), cap.4 sobre conversione, y el rico apéndice documental.

Las cartas de manumisión han sobrevivido tan sólo raramente incluso en los periodos más tardios de la historia valenciana. Véase Leopoldo Piles Hos, Estudio documental sobre el bayle general de Valencia, su autoridad y jurisdicción (Valencia: 1970). pp. 44-46, y los documentos que se incluyen en el apéndice; y especialmente Vicenta Cortés, La esclavitud en Valencia durante el reinado de los Reyes Católicos (Valencia, 1964), pp. 136-140, y los documentos que se incluyen. La conversión no liberaba automáticamente al musulmán. Los Furs del rey Jaume estipulaban incluso en el caso de un musulmán paseído en común que se convirtiera pera que tan sólo uno de los dos dueños quisiera liberarlo, que el dueño generoso debía pagar al otro su parte completa del precio del esclavo (nub. LXXli, número 4).

(2) Véase mi estudio "Social Riots on the Christian-Moslem Frontier (Thirteenth-Century Valencia), American Historical Review, LXVI (1961), 378-400, con el comentario de Ramón Llull sobre conversos del Islam \{p. 381\}, traducido como "Avallots socials a la València del segle XIIl» en mi Jaume li els valencians (Valencia: 1981 ), cap. 6 .

(3) Insertado por el notariọ-escriba sobre la línea. 